\title{
Cheap malaria drug is going to wrong people, says charity
}

This News story incorrectly stated that the US government was one of the two main funders to the affordable medicines facility—malaria (BMJ 2012;345:e7157, doi:10.1136/bmj. e7157). In fact, the US does not support this scheme through funding. The UK government is one of the main funders, as we stated in the 10th paragraph of the story, along with UNITAID.

Cite this as: BMJ 2012;345:e7254

๑ BMJ Publishing Group Ltd 2012 